\title{
Exploration and Exploitation of Good Practices by Technology Parks: Empirical Findings from Poland
}

Anna Wójcik-Karpacz

Jan Kochanowski University in Kielce, Poland

anna.wojcik-karpacz@ujk.edu.pl

Jarosław Karpacz

Jan Kochanowski University in Kielce, Poland

jaroslaw.karpacz@ujk.edu.pl

Joanna Rudawska

Jan Kochanowski University in Kielce, Poland

joanna.rudawska@ujk.edu.pl

In the context of current economic climate in which enterprises revise business models as well as seek new opportunities and their significance for economic growth policies in a situation where the government recognises the need to support micro-, small and medium-sized enterprises, analysing paths for learning good practices by the technology parks (T PS) is a valuable scientific venture. The aim of this article is to identify ways of learning good practices by technology parks operating in Poland. Data collection techniques engaged standardised and unstructured interviews conducted with 14 managers of the technology parks operating in Poland. In the research, the ambidexterity approach was adopted as one that fits into the current trend of strategic management based on paradoxes, assuming the simultaneity of exploratory and exploitative learning. Results showed that in those т PS which were analysed, maintaining attractive offers of support for current and potential beneficiaries is based on the systematic adaptation of already-recognised good practices and experimentation with new good practices. Research findings indicated ambidexterity as a condition which is not alternative, but necessary for the development of тPS.

Key Words: technology parks, best practices, exploration-exploitation, organisational learning, ambidextrous approach

JEL Classification: L26, M1

https://doi.org/10.26493/1854-6935.17.317-334

\section{Introduction}

Dynamic capabilities and their consequences for organisations have been the subject of scientific inquiry for a long time. Despite the fact that 
such research works were generally carried out among enterprises (Bruni and Verona 2009, 101-17; Gebauer, Paiola, and Edvardsson 2012, 321-39; Wójcik-Karpacz 2019, 111-2), this problem equally affects other types of organisations, including technology parks (Т Рs) in which such research was not conducted at all. Changes in the sources of financing $\mathrm{T} P \mathrm{P}$ ' activities in Poland that have been recorded in recent years, which are under the influence of 'withdrawal' of European Union structural funds from existing financing sources and the emergence of a different type of financing, among others, such as local entities, big and small and medium-sized enterprises (SMES) and micro-sized enterprises, encourages them (TPS) to meet the expectations of high quality services reported by entrepreneurs as well as institutions financing services for SMES.

Based on the findings of previous works which indicate that the growing importance of empowerment of clients and other stakeholders than ever before (Urbanowska-Sojkin 2013, 224-35) makes reconfiguration of operational practices more possible, and that requires looking for new ways of doing things. This also applies to the тPS, because they belong to business environment institutions which through their activities are to increase the portfolio of resources available to enterprises and the possibilities of their instrumentation in a commercially viable way (WójcikKarpacz and Mazurkiewicz 2015, 575-90; Wójcik-Karpacz and Rudawska 2016, 248-64). A challenge for the TPS, regardless of their business models, which should follow the development of good practices, is that continuing their operations in each period of time requires them to use dynamic capabilities whose development is highly based on good practices (GPS) (Daniel and Wilson 2003, 282-96). In the modern world of paradoxes, the TPS have to cope with tensions which are evoked by these paradoxes. One of them is the paradox of exploration and exploitation (March 1991, 71-87), if they strive to reconcile adaptive capability with innovation and introducing anticipatory changes. What is more, the eldest Polish technology parks have only 24 years of experience. In comparison to the first US A research parks (1948), they are all still in a development phase, trying to reach competitive advantage also by learning from different sources. Therefore, the aim of this article is to identify ways of learning good practices by the technology parks operating in Poland.

This article extends the previous research and focuses on dynamic units in different sizes. The authors extended results of previous research and found that the technology parks operating in Poland are ambidextrous organisations as well because they use both exploratory and ex- 
ploitative learning of good practices to become and maintain the status of modern and dynamic т Ps. Research findings allow, therefore, to believe that ambidexterity is the right path for developing good practices by the TPS operating in Poland.

\section{Good Practices: Theoretical Approach}

In the literature, the concept of good practices is widely defined. A good practice may be a postulate, guideline or rule which indicates what actions should be taken to perform a specific job more efficiently and effectively. They are defined as: 'methods and tools faster and better than others' (Hoag and Cooper 2006, 151), 'activities aimed at optimal performance of work' (Dani et al. 2006, 1717-28) or 'ways of performing activities in order to improve functioning of organisations' (Codling 1995, 34). There are also examples of referring good practices to the potential of organisation, which results from the accumulated experience of employees. Other authors, in turn, identify good practices with know-how and tacit knowledge (O'Dell and Grayson 2006, 601-22).

Good practices are not only breakthrough and exemplary initiatives, but above all, ways of acting resulting from experience. A basis for considering activity as a good practice is to confirm its effectiveness in solving a specific problem (Kerzner 2009, 373). What is important, operational capabilities are considered strong when a given organisation has achieved the best practices (Pfeffermann 2017, 191-212). This means that the development of TPS' operational capabilities is highly based on the best practices (Daniel and Wilson 2003, 282-96). Technology parks' operational capabilities mean achieving technical efficiency and 'doing things right' in basic business operational, administrative and management functions (Pfeffermann 2017, 191-212). An observable expression regarding the advantages of homogeneous good practices is that one may observe 'similarities' in the activities of technology parks which are successful.

\section{What are Ambidextrous Organisations: Literature Findings}

In strategic management, the uncertain context of environment requires the development of dynamic capabilities. Having such capabilities enables such organisations as technology parks to better perform their functions and, consequently, to contribute to more effective support for innovative enterprises operating in their areas at present and the future. In order for this to happen, technological parks also need to reconfigure their operational capabilities to strike a balance between the explo- 
ration of new good practices and the exploitation of current ones (Kriz, Voola, and Yuksel 2014, 287-99) because both activities are needed for them to survive and develop (March 1991, 71-87). Exploratory and exploitative activities, despite the fact that they seem to be contradictory, do not need to be ruled out, and ambidextrous organisations, thanks to their intelligence, are able to reconcile them (He and Wong 2004, 48194). In the literature, the organisation's capability to balance exploratory and exploitative activities is called ambidexterity (O'Reilly and Tushman 2004, 185-206). Ambidexterity means the organisation's capability to operate in different (oppositional) directions at the same time (Bratnicka 2015, 67-82; Zakrzewska-Bielawska 2017, 174-90). Researchers considering the problem of ambidexterity were focusing on various approaches, placing it, among others, in the theory of organisational learning which is the key trend for intelligent organisations (Nosella, Cantarello, and Filippini 2013, 450-65). Organisational learning refers to the problem of seeking a balance between two competing aims. On the one hand, it is a search for and acquisition of new good practices, i.e. exploration; on the other hand, exploitation of existing good practices, which is based on processes used to improve incrementally existing operational capabilities and knowledge. Exploration leads to adaptation through developing new good practices, while exploitation aims at using existing good practices. In order to achieve high effectiveness in the long term, the TPS must explore good practices, learn new ways of doing things and, at the same time, use good practices which have already been implemented, i.e. select ways to achieve results considered satisfactory over a longer period of time. So if exploration and exploitation are put in opposition to each other, a conclusion may be drawn that both sides of this contradiction are necessary to achieve effectiveness by the T PS in the long run. Ambidextrous organisations must therefore balance exploratory and exploitative learning. It is proved that organisational learning capability positively influences knowledge management and organisational business performance (Turulja and Bajgorić 2018, 1-18; Okreša Đurić and Maleković 2018, 239-46). But, any kind of organisational learning is self-propelling and may lead to falling into a 'success trap' or 'failure trap' (Im and Rai 2008, 1281-96). The theory of organisational learning offers support for understanding the links between the 'success traps' and the development of dynamic capabilities. Literature indicates that when the exploration of good practices displaces exploitation, there is the 'failure trap' (Levinthal and March 1993, 95-112). However, 'success trap' reflects the organiza- 
tion's excessive emphasis on learning through exploitation, or a passive learning process based on experience which focuses on operational routines and replication of operational capabilities, and thus replication of previously used good practices. This makes it difficult to enter a higher level of intentional learning in order to change the status quo and develop new knowledge and operational capabilities. Therefore, if the т PS successfully improve their capabilities and increase their effects resulting from exploitation of good practices, their willingness to change decreases. As a consequence, the possibilities to influence changes in the environment may be suppressed, and the most important good practices related to recent successes become, over time, the most inflexible element of such technology parks (Karpacz 2017, 375). But any success achieved in the past is a predictor of existing capabilities and does not always lead to the 'success trap.' Only those technological parks which experience organisational inertia preventing them from breaking the bonds of existing good practices fall into it; while the environment changes, they remain in a trap of the recent success (Karpacz 2017, 373). Therefore, the technology parks' managers should avoid sinking into the trap of existing good practices resulting from past successes and cautiously develop new ones allowing them to respond to changes in the environment. What is important, 'success traps' may have a greater impact on the results of technology parks than 'failure traps.' The immediate value of information about success is higher than that about failure. Information about success tells employees what is going on; while information about failure excludes one of many possible directions of action (Wang, Senaratne, and Rafiq 2015, 26-44). To explore good practices, the technology parks simultaneously use resources and their ability to create and capture values from new good practices which their top management has identified as the most promising ones. At the same time, adopting new good practices may require the selective withdrawal of old practices, and will even require changing business models of some parks (Dyduch 2017, 253-66).

In reference to the above literature findings, the question arises whether ambidexterity is necessary for the survival and development of all T PS, or only those whose industry profile belongs to the high-tech industry due to relatively much higher expectations of enterprises - TPS' tenants resulting from the latest scientific, technical and technological achievements? Literature findings indicate that while organisations operate in hyper-competitive environments, ambidexterity is perceived as a key success factor; while in a relatively stable environment (of less complexity 
and dynamics of change as well as greater predictability), it is not necessarily like that (Kriz, Voola, and Yuksel 2014, 287-99). The current state of research does not give a clear answer to the above question. On the one hand, it indicates that in conditions of a complex and constantly changing environment, and such one occurs in the high-tech industry, the technology parks should shape and develop dynamic capabilities and, at the same time, their ability to balance exploratory and operational activities (Kriz, Voola, and Yuksel 2014, 287-99) which are guided by other strategic aims (He and Wong 2004, 481-94). These findings indicate that in such conditions ambidexterity allows the technology parks to cope better. On the other hand, it suggests that the technology parks which address their offer to enterprises operating under more stable conditions may be less inclined to shape and develop ambidexterity because the environment protects them to some extent. Therefore, for this type of technology parks, ad hoc problem solving may be more cost-effective than creating dynamic capabilities in case they have to react to a non-typical and/or temporary change in the needs of enterprises - TPs' tenants. Continuing this discussion, it is reasonable, however, to pay attention to the fact that the current negligence of investments in developing new good practices, although having high efficiency in the present, has poor prospects for the future. Having all this into consideration, although much has already been explained about ambidexterity in the literature, this does not concern such organisations as technology parks, because so far such research has not been conducted. Filling this cognitive gap out found its expression in the subsequent parts of this article.

\section{Description of Research Sample and Data Collection}

\section{RESEARCH TECHNIQUES}

Data collection techniques engaged standardised and unstructured interviews conducted with 14 managers of the technology parks operating in Poland. Over $1 / 3$ of the general population was analysed.

Questions were being asked in the same order and were open-ended. During the research, the interview scenario was being used, but the questions were being asked in a free manner and on the basis of the so-called thematic threads. These questions allowed for obtaining a lot of valuable information and gave the opportunity to structure certain pieces of information. During the interviews, the information about how the technology parks explore and exploit good practices was obtained, among oth- 
ers. After the transcription of interviews, the collected data was subjected to further analysis. The results of grouping and comparing respondents' profiles are presented in the next part of this article.

\section{DATA}

Pilot qualitative empirical research on how to learn good practices by the technology parks were being conducted from September 2018 to March 2019.

General population consisted of 37 technology parks operating in Poland (as of 1 September 2018). Due to the fact that a 'technology park' construct is commonly used for each type of park in the literature, this construct was also used to define the different names of parks functioning in practice (Wójcik-Karpacz 2019, 111-12).

Exploratory and exploitative learning of good practices was considered as an organisational phenomenon. Organisational level of analysis of this phenomenon was an argument for engaging managers of technology parks as respondents, as they have adequate knowledge about the activities of the organisations by which they are employed.

\section{Ambidextrous Organisations in Practice: Research Findings}

Ways of technological parks' behaviour, which may be more oriented to exploitation or more to the exploration of good practices, were the reasons for asking a research question: how do the technology parks operating in Poland learn good practices? Recognising these ways of technology parks' behaviour gives insight into their learning methods which, at the same time, are the basis for recognising them as ambidextrous organisations, or not.

Analysis of the content of responses provided by the TPS' managers made it possible to identify the paths of exploratory learning of good practices by the TPS operating in Poland.

\section{WAYS OF EXPLORATORY LEARNING OF GOOD PRACTICES}

\section{BY TPS}

TP1 Entrepreneurs, technical university.

While talking with an entrepreneur, by a university, by a technical university (department of machine construction). Not from other parks or from abroad.

T 22 Employees who take part in international projects, clients.

If we see something good, we try to transfer it, we read a lot, we are 
taught a lot by life, employees, clients who force us to do it; we are a commercial park, if something is wrong, we have nothing to live on.

TP3 Domestic trade fairs, foreign parks, and institutions.

In general, trade fairs when it comes to business, and traveling around the world and seeing different places when it comes to a public sphere.

TP 4 Foreign parks.

We draw much from abroad, examples of internationalisation of enterprises.

TP5 TPS'employees participating in international projects, workshops, study visits, other workshops, foreign parks, foreign incubators, foreign accelerators.

Abroad, to a large extent, and basing on the workshops we have been to or in projects, in the Interreg projects like FastForward where we have partners from 11 European countries and we visit and meet each other in incubators, accelerators; so there, for sure. Moreover, a lot of our staff graduated the Top 500 programme (4 persons), we are steeped in that. Also, from the staff in our park.

т 6 National media, network of employees' social relations, letters of intent, mutual cooperation agreements, foreign media, other domestic and foreign parks, business environment organisations, domestic and foreign conferences.

We have a two-dimensional model of communication in terms of our good practices. The first one comprises signed letters of intent and agreements on mutual cooperation; the second one involves foreign and domestic media, groups of parks cooperating with us, and we participate in all possible conferences in order to exchange experiences and search for new solutions. We are currently implementing a few projects in a public sphere, namely for the Ministry of Justice and the Ministry of Science and Higher Education, and we establish cooperation through consulting companies, but also private knowledge of park's employees in the use of $\mathrm{E} U$ funds, acquisition of money for expansion and introduction of new products or services, mainly due to the fact that the park is scientific, it has that part in the name and commercialisation is very difficult and we have to look for sources of financing, which is not easy, but we more and more often succeed.

TP7 Employees, study visits, membership in international associations. 
We travel and it is always very inspiring, we read, we are present in international associations and it also allows us to keep our finger on the pulse.

T 8 Domestic and foreign study visits in other TPS, other organisations.

Mainly during domestic and foreign study visits where we look for inspiration, we look at what proves itself in other technology parks, and we wonder if it can be applied in ours, but also in other organisations which are not parks, but some of their activities can be translated into our case.

TP9 Employees, other domestic TPS, study visits.

There are two channels, it can be said that on the one hand there are experiences of other parks; here, we try to cooperate with parks of our region, there are 3 technological parks in the region, which are partners with each other in terms of services they provide. We have very partner relationships, we do not become competitors, even when we apply for funds, even from the same source; all of this does not make us not try to be partners and exchange our experiences. The second channel concerns meetings abroad, that is, some trips, but also an analysis of everything that is happening in the world, through a review of the literature.

TP10 Employees.

Based on our own experience, we come up with what could be catchy and then we try to organise it.

TP11 Other domestic and foreign TPS.

We have been traveling for a long time, we observe various solutions in Europe and the United States and in Poland, and since the very beginning we have seen this model of the park and known how this model should function.

TP12 Employees, other domestic and foreign TPS, other organisations, including those belonging to business environment institutions.

Observing and following other technology parks are obviously one of the basic methods of drawing inspiration to use good practices. First of all, these are practices implemented in organisations with a similar business profile; and secondly, we can get first-hand feedback about the benefits of implementing a given solution. We often observe other organisations which partially implement similar or the same tasks as our TP, but they are not technology parks. For example, due to a similar field of operation, we are eager to use the experi- 
ence of the Polish Chamber of Chemical Industry (PCCI) which implements a number of information, education and lobbying tasks for the broadly-understood chemical industry. On the other hand, there are many institutions dealing with investor services, such as Special Investment Areas or the Polish Investment and Trade Agency, which are also observed by us in terms of their standards and effects of their work.

TP13 Improvement of procedures used in own TPS so far, mainly other domestic TPS of a similar industry profile, other business environment institutions.

Good practices in the Science and Technology Park (st P) in Opole originate mainly from inspiring by practices in other parks or by improving already implemented procedures. Carrying out evaluation surveys among clients, thanks to which we know what to improve in our practices.

S T P in Opole as one of the youngest parks in Poland draws huge inspiration from the activities of other parks and systematically monitors good practices implemented by them. We mainly take examples of parks of a similar business profile (conducting research and development activities and in the field of Iт).

We often observe and exchange good practices with other institutions of business environment (IBE) in the Opolskie region, among others, Opole Chamber of Commerce, Opolskie Centre for Economy Development, Opole Center for Local Democracy. We observe them in terms of educational or project tasks.

TP14 Employees, other domestic and foreign TPS, study visits, project meetings, investment missions, thematic workshops, conferences, thematic publications.

Mainly from other parks, we go there and observe. We participate in project meetings, study visits, investment missions, we ask in detail what and how works well for them, what has not been met with interest, we take pictures. Identification of good practices and their transfer among different centres usually take places through thematic workshops, conferences, study visits or publications in this field.

Research results indicated the existence of various paths of exploratory learning of good practices by the technology parks. Study visits at other domestic and foreign TPS are a very common way of acquiring knowl- 
edge about good practices and then copying them in own organisation. Technology parks also share information about good practices at regularly organised thematic conferences, meetings as part of ongoing projects and, sporadically, during thematic workshops. A frequent method of developing good practices is the experience of technology park's employees who, during their day-to-day operations for enterprises functioning both within the TPS and external ones using the TP's services or infrastructure, discover further opportunities to enrich the offer.

On this basis, it may be assumed that only the best practices are important from the perspective of employees working in various positions in the organisational hierarchy. Employees share the best practices and want to replicate successes of other TPS, which supports the argument that successes are more important than failures.

However, it should be borne in mind that although good practices copied have some similarities, they differ among the technology parks which apply them due to specific factors (such as personnel and managerial staff; modern infrastructure and technology; size of office and laboratory space; equipment in laboratories, etc.), as well as internal processes necessary for their implementation, which lead to various results. Technology parks which regularly improve and reproduce their good practices shall probably have an advantage over those which are slower in this respect. In addition, they can make better use of the situation of relative stability in their environment to prepare themselves for more drastic changes at a later date, and even to create ground-breaking changes in their offer. In practice, this means that the technology parks are not focused on solving problems mainly through the further development of existing good practices. However, the implementation of new good practices should not lead to negligence or unreasonable rejection of existing 'proven' good practices, but to complement them. To some extent, the recognition of this issue is brought by subsequent fragments of managers' responses about the TPS' ways of using good practices.

WAYS OF EXPLOITATIVE LEARNING OF GOOD PRACTICES BY TPS

TP1 Employees, enterprises - TP s' tenants.

Nobody will understand services in the park without going to a laboratory and not seeing how employees cooperate with an enterprise while making measurements there.

TP2 Employees, TPS' managers, enterprises - TPS' tenants. 
There are some standards which must be fulfilled, but all other things must dynamically change. If it is good, it is ok. Everything is forced by the market, we are trying to keep high standards. Usually, we try bottom-up implementation, because it is the best then. Not in a way that I will come up with something, but it originates from employees. Those who have the first contact with clients. They know their needs and are able to communicate them to the management which then is able to take further actions.

TР 3 Employees, benchmarking of good practices in other TPS as a reference point for modification of good practices by a park, clients.

Implementation by mapping. There is no such thing as stability, in the long run, every day brings new challenges, needs and this good practice is modified; it must be located in a place where it is implemented and adapted to the culture, needs and resources, and so on.

TP 4 Employees, benchmarking of good practices in other TPS.

We are implementing everything step by step, checking whether, for example, the 'SME Internationalisation Exchange' (SIE) project works, where we absorb practices and promote our solutions by ourselves.

TP5 Employees, benchmarking of good practices in other TPS.

We are trying to carry out implementation activities very hard, because some things which we have borrowed from somewhere, for example, from Spain, a new thing (it does not exist in Poland) we want, let say, to implement in our park. So firstly, we will try and practice it on a smaller group and then implement it somehow among our tenants, and on outside, as well.

TР 6 Employees, benchmarking of good practices in other TPS, including foreign ones, benchmarking of good practices among enterprises operating in TPS in various countries.

It is not always a constance. It evolves over a long period of time. We expect that there will be an even more competitive solution, that is matched. Sometimes it evolves in a direction we have assumed, and sometimes it evolves in a completely different direction. The example of an incubator, which we saw during the visit in China, showed us that small and medium-sized enterprises are developing, and we have enterprises which work with Apple, Microsoft. So even our small businesses can exchange experiences with Chinese ones.

TP7 Employees, enterprises - TPS' tenants. 
We implement them and adapt them to our needs and the needs of our clients.

Т 8 Employees while performing operational activities for enterprises/communicating needs by enterprises operating on the TPS' areas.

While continuing good practice, we expect that it will continue to prove itself in practice. There are services which do not evolve and it is enough that this standard is good, and we maintain it. It has to be adapted all the time, only the scheme/draft can be the same. One has to evolve all the time to develop. When it comes to the scope of consultancy services for enterprises from other parks, they function to this day, although they are slightly changed.

TP9 TPS'business model, employees, enterprises - TPS' tenants.

I will refer to what I have said regarding all services, but also a certain concept of park management. In the long run, that is at the moment of introducing a good practice, we try to define how we understand it, how we will take these actions to implement it. But it is also acting somehow on a living organism on whose other side is a subject which is a recipient, it has expectations, and its expectations do not have to be consistent with what we assumed at the beginning, so as a result of cooperation, this final shape is given.

TP10 Employees.

We assume that the enterprises will cooperate with each other, not only door to door, but also building to building, as we have 4 buildings and it must be animated so that everyone knows each other.

TP11 Employees.

From the very beginning we have been implementing and applying such a practice, we provide enterprises with a certain infrastructure for the beginning of their operations, then some of the enterprises have their infrastructure, a rented part, and this barrier to entry into the high technology industry is overcome in that way. These are, of course, risky projects, because the investment risk falls on the park, failure of the project made on the park's infrastructure imposes on the park the necessity of looking for a new client and incurring losses in the period of when this infrastructure was out of use. But thanks to this, several and even several dozen very good high technology entities were established and it is worth doing it.

T 12 Employees while performing operational activities for enterprises and meetings with entrepreneurs. 
Firstly, the Płock Industrial and Technological Park (PIT P) tries to use good practices in its own organisation.

However, there are cases where some good practices are not available for use by the PITP, if only due to a different size or organisational structure, or because of different scope of tasks we implement. However, we try to pass on information about good practices further. As a majority shareholder of Centrum Edukacji Sp. z o.o. we pass this knowledge and influence its implementation to this company. We also share some good practices during our meetings with entrepreneurs gathered in the PIT P, Chemical Cluster or in general with enterprises which participate in our events.

TP13 Employees, TPS'managers.

Before implementation, good practices are discussed at employee meetings, and then presented to the Board of Managers for verification and acceptance. We implement such a practice 'experimentally' to check its effectiveness. If it is accepted, we implement it permanently and if it is necessary, we try to improve it even more so that it can be adapted to our needs.

TP14 Employees, TPS'managers.

As we have a good practice, we test it, because it is a very important stage; we modify, for example, a recruitment process, we separate stages and questions being asked. Then, we test again and implement it after the corrections with appropriate provisions, e.g., an ordinance.

Processes change over time because they evolve, are improved and become 'our action' based on a previously discovered and 'followed' good practice. We often pass them on meetings, presentation displays and conferences where we share our knowledge. But, the quality of servicing clients is always the result, nothing changes here.

Answers of technology parks' managers indicate that exploitative learning of good practices permeates all hierarchical levels of these organisations, usually from staff to top management. At the same time, it is exposed in different ways and to different degrees in individual T PS.

Top management strengthens the entrepreneurial behaviours of managers of lower levels and personnel members. Managers of different levels of technology parks' management recognise and cultivate as well as manage and encourage bottom-up initiatives of employees and representatives of other scientific and business institutions, thanks to which trans- 
forming results of research and development projects into technological innovations may become much faster and more effective, as well as improve the тPs' effectiveness and functioning, at the same time.

In this bottom-up approach, the entrepreneurial behaviour of personnel members is therefore a key mechanism enabling not only the implementation of aims set for individual technology parks, but above all, to guarantee access to modern infrastructure and technology. In this case, the behaviour of т P s' employees is also strongly associated with exploitative learning of good practices and is of an entrepreneurial, but not inhibitory nature.

These findings indicate that technology parks striving to provide convenient development conditions create effective solutions, especially in the area of systematic matching of their offer to the needs of enterprises which are or will be the TPS' tenants.

\section{Conclusions and Summary}

This article presents empirically verifiable knowledge about exploratory and exploitative learning as paths for the development of good practices by the analysed technology parks in Poland were presented. Research findings indicate that neither exploitation nor exploration may be dispensed with as both of these activities are needed to maintain modern and dynamic technology parks which facilitate the development of enterprises operating in the areas administered by them. Image of the analysed technology parks operating in Poland, which emerged after conducting a kind of 'inventory', shows exploratory and exploitative activities within the same park and a balance between them. This means that ambidexterity is the right path for developing good practices. Practices recognised as the best ones become a desirable standard. Hence there are searching for them and then they are followed. TPS may be treated as ambidexterious organisations because they simultaneously carry out exploratory and exploitative activities, reconciling the tensions which arise between them. Implementation of such a reciprocal approach by the TPs is difficult because exploration and exploitation require different models of organisational learning, as well as various components of resources and capabilities whose implementation provides the technology parks with specific benefits, primarily in the form of increased efficiency and effectiveness of operations as well as growth in innovation. Therefore, the technology parks which may now be falling into 'success trap' or 'failure trap', will probably transform into ambidextrous organisations over time in or- 
der to benefit not only from new knowledge and searching for new good practices, but also from operational efficiency and good practices already used.

\section{PRACTICAL IMPLICATIONS}

A very often implemented method of learning good practices lies in the potential of technology parks themselves, the source of which is the accumulated experience of managers and non-managers, both through exploratory and exploitative learning of good practices. This proves that the technology parks' managers do not lose sight of long-term efficiency, which may be ensured by successive good practices. To conclude, it may be stated that the TPS make strategic integration between these activities in an effort to maintain balance. In practice, it means that these technology parks which improve and reproduce good practices will have an advantage over those which are slower in this respect.

\section{LIMITATIONS AND SUGGESTIONS FOR FUTURE \\ IMPLICATIONS}

With regard to qualitative research, there is a doubt as to its universality (to what extent will particular cases allow for understanding other cases) and objectivity (or if another respondent perceived a given phenomenon in the same way).

Conclusions and generalisations refer only to part of the parks' population units because the research sample is not representative. However, the research results may form the basis for comparative research in the field of learning of good practices by the technology parks.

In the future, it is recommended to analyse the antecedences of selection of exploratory and exploitative learning by technology parks and results obtained in connection with their implementation. Also, an interesting direction of further research seems to be a deeper recognition of the context not only from the perspective of strategies, structures or processes, but also the competence and commitment of managerial staff.

\section{References}

Bratnicka, K. 2015. 'Reconsideration of Organizational Ambidexterity: A Dialectical Multilevel Approach.' International Journal of Contemporary Management 13 (4): 67-82.

Bruni, D. S., and G. Verona. 2009. 'Dynamic Marketing Capabilities in Science-Based Firms: An Exploratory Investigation of the Pharmaceutical Industry.' British Journal of Management 20 (1): 101-17. 
Codling, S. 1995. Best Practice Benchmarking: A Management Guide. Aldershot: Gower.

Dani, S., J. A. Harding, K. Case, R. I. M. Young, S. Cochrane, J. Gao, and D. Baxter. 2006. 'A Methodology for Best Practice Knowledge Management.' Journal Engineering Manufacture 220 (10): 1717-28.

Daniel, E. M., and H. N. Wilson. 2003. 'The Role of Dynamic Capabilities in E-Business Transformation.' European Journal of Information Systems 12 (4): 282-96.

Dyduch, W. 2017. 'Strategiczny projekt organizacji wspierający rozwój zdolności dynamicznych.' In Strategiczny wymiar dynamicznych zdolności polskich przedsiębiorstw, edited by K. Krzakiewicz and Sz. Cyfert, 253-66. Poznań: Wydawnictwo UEP.

Gebauer, H., M. Paiola, and B. Edvardsson. 2012. 'A Capability Perspective on Service Business Development in Small and Medium-Sized Suppliers.' Scandinavian Journal of Management 28 (4): 321-39.

He, Z. L., and P. K. Wong. 2004. 'Exploration vs. Exploitation: Empirical Test of the Ambidexterity Hypothesis.' Organization Science 15 (4): 48194.

Hoag, B., and C. L. Cooper. 2006. Managing Value-Based Organizations: It's Not What You Think. Cheltenham: Edward Elgar.

Im, G., and A. Rai. 2008. 'Knowledge Sharing Ambidexterity in Long-Term Interorganizational Relationships.' Management Science 54 (7): 128196.

Kerzner, H. 2009. Project Management: A Systems Approach to Planning, Scheduling and Controlling. Hoboken, NJ: Wiley.

Kriz, A., R. Voola, and U. Yuksel. 2014. 'The Dynamic Capability of Ambidexterity in Hypercompetition: Qualitative Insights.' Journal of Strategic Marketing 22 (4): 287-99.

Levinthal, D. A., and J. G. March. 1993. 'The Myopia of Learning.' Strategic Management Journal 14 (s2): 95-112.

March, J. G. 1991. 'Exploration and Exploitation in Organizational Learning.' Organization Science 2 (1): 71-87.

Nosella, A., S. Cantarello, and R. Filippini. 2013. 'The Intellectual Structure of Organizational Ambidexterity: A Bibliometric Investigation into the State of the Art.' Strategic Organization 10 (4): 450-65.

O'Dell, C., and C. J. Grayson. 2004. 'Identifying and Transferring Internal Best Practices.' Handbook on Knowledge Management 1:601-22.

Okreša Đurić, B., and M. Maleković. 2018. 'Knowledge Management and Conceptual Modelling Towards Better Business Results.' In Proceedings of the ENTRENOVA - ENTerprise REsearch InNOVAtion Conference, 239-46. Zagreb: IRENET - Society for Advancing Innovation and Research in Economy. 
O'Reilly, C. A., and M. L. Tushman. 2008. 'Ambidexterity as a Dynamic Capability: Resolving the Innovator's Dilemma.' Research in Organizational Behavior 28:185-206.

Pfeffermann, N. 2017. 'Role of Communication as a Dynamic Capability in Business Model Innovation.' In Revolution of Innovation Management, edited by A. Brem and E. Viardot, 191-212. Hamburg: Hochschule Hochschulzentrum Hamburg.

Turulja, L., and N. Bajgorić. 2018. 'Knowing Means Existing: Organizational Learning Dimensions and Knowledge Management Capability' Business Systems Research 9 (1): 1-18.

Urbanowska-Sojkin, E. 2013. Ryzyko w wyborach strategicznych w przedsiębiorstwach. Warszawa: Polskie Wydawnictwo Ekonomiczne.

Wang, C. L., C. Senaratne, and M. Rafiq. 2015. 'Success Traps, Dynamic Capabilities and Firm Performance.' British Journal of Management 26 (1): $26-44$.

Wójcik-Karpacz, A. 2019. Zdolności organizacyjne w kontekście wyników przedsiębiorstwa: aspekty teoretyczne $i$ wyniki badań empirycznych. Warszaw: Polskie Wydawnictwo Ekonomiczne.

Wójcik-Karpacz, A., and Mazurkiewicz, Sz. 2015. 'Rola parków technologicznych w kształtowaniu przedsiębiorczego rozwoju przedsiębiorstw.' Marketing i Rynek 5: 575-90.

Wójcik-Karpacz, A., and J. Rudawska. 2016. 'Instytucjonalne formy wspierania przedsiębiorczości w Polsce.' Prace Naukowe Uniwersytetu Ekonomicznego we Wrocławiu 419:248-64.

Zakrzewska-Bielawska, A. 2017. 'Ambidexterity jako zdolność dynamiczna $\mathrm{w}$ odpowiedzi na niepewność otoczenia.' Studia Oeconomica Posnaniensia 5 (9): 174-90.

This paper is published under the terms of the Attribution-

NonCommercial-NoDerivatives 4.o International (CC B Y-NC-ND 4.0)

License (http://creativecommons.org/licenses/by-nc-nd/4.o/). 